\title{
Influencia de los periódicos españoles en la creación de estereotipos contra los inmigrantes marroquíes entre los años 2008 y 2016
}

\section{Influence of Spanish newspapers on the creation of stereotypes against Moroccan immigrants}

\author{
Alba Marina González Martínez, Iara Maribondo Albuquerque \\ Khalil da Costa Silva y José Luis Álvaro Estramiana
}

Universidad Complutense de Madrid, España

\begin{abstract}
Resumen
La presente investigación se ha centrado en analizar los discursos que los principales periódicos españoles utilizan para representar al colectivo marroquí en España. Para el tratamiento de la información recogida fueron adoptados los principios de la Teoría del Framing. Se analizaron los títulos de artículos periodísticos que incluyesen la palabra "marroquí" de tres periódicos nacionales, "El Mundo", "ABC" y "El País", publicados entre los años 2008 y 2016. Los análisis de contenido textual fueron realizados por medio del software IRAMUTEQ. En los tres diarios predominaron clases que ofrecían una imagen negativa del colectivo marroquí, transmitiendo una percepción de amenaza, tanto real como simbólica. Esta investigación contribuye a la comprensión de cómo los medios de comunicación colaboran en la conformación de estereotipos negativos frente al colectivo marroquí, legitimando situaciones de discriminación de esta minoría social.
\end{abstract}

Palabras clave: Inmigración, estereotipos, discriminación, marroquí, medios de comunicación.

\begin{abstract}
The present research has focused on analyzing the speeches used by the most important Spanish newspapers to represent the Moroccan collective in Spain. For the treatment of the information collected, the principles of the Framing Theory were adopted. To carry out this study, it were analyzed the titles of newspaper articles that included the word "Moroccan" from three national newspapers, "El Mundo", "ABC" and "El País" published between the years 2008 and 2016. The analysis of textual content were made through the IRAMUTEQ software. In the three newspapers, the predominant classes offered a negative image of the Moroccan collective, transmitting a perception of threat, both real and symbolic. This research contributes to the understanding of how the media collaborate in the formation of negative stereotypes towards the Moroccan collective, legitimizing situations of discrimination against this social minority.
\end{abstract}

Key words: Immigration, stereotypes, discrimination, Moroccan, mass media.

Artículo recibido el 28 de agosto de 2019 y aprobado el 06 de agosto de 2020. 


\section{INTRODUCCIÓN}

$\mathrm{D}$ esde el año 2008 en España se ha producido un descenso de la población extranjera como consecuencia de la crisis económica. Sin embargo, la percepción que mantiene la población autóctona al respecto difiere de la realidad. En un estudio realizado por Cea D’Ancona y Vallés (2014), 38 por ciento de los encuestados consideraba que el número de inmigrantes que había en España era excesivo, y un 34 por ciento que era elevado.

Las consecuencias (deterioro de las condiciones de trabajo, desempleo, incertidumbre y recortes del Estado de Bienestar) de la crisis económica que ha afectado a Europa desde 2008, están relacionadas con el aumento de las actitudes xenófobas por parte tanto de la población europea en general y española, más específicamente. El apoyo a políticas restrictivas en la admisión de inmigrantes ha experimentado un considerable aumento, sobre todo en aquellos países en los que las tasas de paro son más altas. Todo ello guarda una estrecha vinculación con el auge que han sufrido en Europa los partidos de extrema derecha, los cuales sostienen valores extremamente conservadores y una clara postura anti-inmigratoria (Artiles, Molina y Meardi, 2011).

Investigaciones previas han demostrado que uno de los grupos más susceptibles de sufrir exclusión social son los inmigrantes (Serrano, 2014; Tezanos y Tezanos, 2006). Este fenómeno se produce cuando un conjunto de personas se ven aisladas o apartadas de una serie de derechos (empleo, vivienda, integración social o apoyo institucional) que se consideran fundamentales del Estado de Bienestar propio de los países desarrollados. Esta situación provoca graves consecuencias en el colectivo afectado, tanto a nivel económico (situación de pobreza y desempleo), como social (aislamiento y ruptura social) y psicológico (pérdida de autoestima, desarrollo de una identidad social negativa o aumento de las conductas agresivas) (Molero, Navas y Morales, 2001).

La exclusión social hacia los inmigrantes puede estar relacionada con diversos procesos de discriminación caracterizados por el trato derogatorio o injusto hacia determinadas personas por pertenecer a un determinado grupo social. La discriminación conlleva, por tanto, un trato negativo o la emisión de respuestas menos positivas, en com- 
Influencia de los periódicos españoles en la creación de estereotipos ...

paración con las que emitiríamos hacia el propio grupo en situaciones comparables. Estos comportamientos crean, mantienen y refuerzan las desigualdades sociales (Dovidio, Hewstone, Glick y Esses, 2010). La discriminación está asociada a otros dos procesos como son el prejuicio y los estereotipos. El primero representa la actitud negativa hacia una persona por el hecho de pertenecer a un determinado grupo social (Allport, 1954). Los prejuicios étnicos a menudo motivan sentimientos y conductas negativas hacia colectivos inmigrantes (Durán y Jiménez, 2006). A su vez, los estereotipos conforman el componente cognitivo del prejuicio, pues constituyen un conjunto de creencias generalmente negativas sobre las características asociadas a un determinado grupo; estos esquemas cognitivos nos ayudan a procesar información, conformando nuestras expectativas sobre el comportamiento de los miembros de diferentes grupos sociales (López-Rodríguez, Cuadrado y Navas, 2013). Los estereotipos tienden a ser creados y difundidos en tres condiciones: (1) para comprender acontecimientos sociales complejos; (2) para justificar acciones cometidas en contra de estos grupos; (3) para diferenciar positivamente el endogrupo del exogrupo (Tajfel, 1981).

Los estereotipos y prejuicios hacia la población inmigrante han sido reforzados por la crisis económica. En este contexto, se produce un incremento de los sentimientos negativos hacia los inmigrantes, ya que la población autóctona siente que sus rasgos culturales o su identidad nacional, están amenazados por su presencia. (Cea D'Ancona, 2009a). En España uno de los grupos de inmigrantes que más se ve influido por los procesos derivados de la estereotipia y el prejuicio, es el colectivo marroquí, siendo también el que sufre más exclusión social y discriminación por parte de la población autóctona, respecto a otros colectivos como el rumano o ecuatoriano (Basabe y Bobowik, 2013; Camino et al., 2013; López-Rodríguez, Cuadrado y Navas, 2013).

La discriminación hacia este grupo está relacionada con el incremento del sentimiento anti-musulmán que se está produciendo en Europa (Ekman, 2015). Este fenómeno se encuentra estrechamente vinculado al auge que están viviendo los partidos de extrema derecha, como consecuencia de los atentados acaecidos en los últimos años y las repercusiones de la crisis económica. Estos partidos, sostienen en sus intervenciones en los medios de comunicación, que los musulmanes representan una amenaza a la seguridad y los valores de la cultura occidental (Appel, 2012; Ekman, 2015). 
Un ejemplo de lo anteriormente indicado lo podemos encontrar en el barómetro realizado por el Centro de Investigaciones Sociológicas en 2014 en el que se hace referencia al modo en el que la población autóctona española percibe los derechos sociales de los inmigrantes. Aunque la mayoría de la población reconoce que los inmigrantes deberían tener acceso a un servicio de sanidad pública, casi la mitad de la población piensa que los inmigrantes reciben más asistencia sanitaria que los propios españoles, y que su presencia conduce a la disminución de la calidad de estos servicios. En este mismo barómetro (CIS, 2014), cuando se le preguntaba a los encuestados "Y, cuando se habla de inmigrantes que viven en España, ¿en quiénes piensa Ud. de manera más inmediata?" El primer lugar lo ocupaba el colectivo marroquí. Además, este colectivo era uno de los que menos simpatía y hostilidad generaba en la población autóctona, ocupando el segundo lugar por detrás del colectivo rumano (CIS, 2014). Los sentimientos de amenaza, tanto real como simbólica, guardan un estrecho vínculo con los procesos de discriminación hacia este colectivo social. La amenaza real surge cuando el otro grupo se comienza a percibir como un riesgo para la salud, el bienestar, o el estatus económico y político de la población autóctona. Por otro lado, la amenaza simbólica se desarrolla como consecuencia de las diferencias culturales, de normas, valores o creencias existentes entre la población autóctona y el grupo inmigrante (Cea D’Ancona, 2017; Ward, Szabo y Stuart, 2016).

En el caso de inmigrantes que provienen de una cultura mayoritariamente musulmana, estos son a menudo percibidos por la sociedad occidental como una amenaza a la homogeneidad cultural occidental. Este sentimiento está fuertemente condicionado por el tamaño del exogrupo (al igual que la amenaza económica) y sus orígenes culturales y religiosos (Cea D’Ancona, 2009b; Cea D’Ancona, 2015). Concretamente, la cultura musulmana se suele percibir como estática y autoritaria, provocando un atraso en su desarrollo social y cultural, lo que resulta incompatible con nuestra cultura occidental. Esta percepción ha ganado fuerza en los discursos islamófobos en los que el principal argumento está constituido por la idea de que la cultura musulmana supone un riesgo para nuestra cultura y el sistema de valores internos que la sustentan (Cea D'Ancona, 2009b; Ekman, 2015). 


\section{Papel de los medios de comunicación}

En este contexto en el que los inmigrantes son percibidos como una amenaza para la cultura occidental, será considerado el papel que los medios de comunicación desempeñan. Éstos ejercen una importante labor como transmisores de información, ya que conforman la mayoría de los conocimientos, opiniones, creencias, valores y comportamientos que mantiene la sociedad (Vieira, 2014). Las preocupaciones y muchas de las cuestiones que captan la atención de la gente, no provienen de su experiencia directa, sino de los medios de comunicación que actúan como la principal fuente de información (D’Adamo y García, 2007). Investigaciones previas como la realizada por Dovidio et al. (2010) y Vieira (2014), sostienen que los medios de comunicación contribuyen a la construcción de los estereotipos que conforman las actitudes y comportamientos que mantendrá la población respecto a los inmigrantes.

Los medios de comunicación aumentan la importancia y saliencia de unos temas sobre otros en su agencia mediática, repercutiendo en la aproximación de la gente a la realidad social. Este efecto ha motivado el desarrollo de la Teoría del Framing. El término "frame", traducido al español como "encuadre", fue inicialmente acuñado por Bateson (1955), en el campo de la psicología. Este autor establece que los frames representan estructuras de la psique que organizan la percepción del sujeto, destacando unos aspectos de la realidad sobre otros. Posteriormente, Goffman (1974), uno de los principales precursores en el estudio de los frames, retoma este concepto y lo traslada al campo de la sociología. Concibe estas estructuras tanto como marcos sociales, al designar el contexto de la realidad, como esquemas mentales, al internalizar datos objetivos de la realidad. De este modo, en los frames se fusionarían dos niveles de interpretación, el individual y el social, ya que una misma realidad puede tener significados particulares para cada individuo, pero también existe una realidad común a todos los individuos de una sociedad. Goffman enfatiza el papel que desempeñan los medios de comunicación en la construcción de la realidad, ya que la forma de describirla tiene una gran influencia en la modificación o perpetuación de determinados marcos sociales y, por ende, en la creación del discurso social compartido (Ardévol-Abreu, 2015; Muñiz, 2007; Sádaba, 2001). 
Durante los años 60, el concepto de frame ha sido ampliamente empleado en el estudio de los movimientos sociales. Posteriormente, a partir de la década de los 80, se ha aplicado en el campo de los medios de comunicación (Sádaba, 2001). No obstante, actualmente no se ha conseguido establecer una teoría unificada del Framing con un objeto de estudio claramente definido. Ello se debe a diversas causas, entre ellas, las múltiples definiciones de "encuadre noticioso" existentes, o sus diversos antecedentes teóricos, desde el ámbito tanto psicológico como sociológico. Sin embargo, cabe destacar una de las definiciones más citadas, la aportada por Entman (1993), quien define el framing como "la selección de unos aspectos de la realidad sobre otros, promoviendo una determinada definición de un problema, explicación causal y/ o tratamiento" (Muñiz, 2007; Vliegenthart, 2012).

Diversos autores han diferenciado dos procesos presentes en el efecto de framing, el encuadre mediático ("media frame") y el encuadre del público ("audience frame"). El primero alude al modo en el que los periodistas identifican y clasifican la información con el fin de reducir su complejidad y aumentar su accesibilidad al público que la recibe. Este proceso motiva una determinada interpretación (causas, evaluación moral o recomendación de tratamiento) de la información presentada. Por su parte, el "audience frame" hace referencia al conjunto de esquemas de interpretación que permiten a los individuos procesar la información que reciben y formar sus propias impresiones sobre el mundo. Estas estructuras psicológicas pueden asimilarse con esquemas cognitivos que están condicionadas por los diversos factores sociales y culturales que rodean al individuo (Ardévol-Abreu, 2015; Muñiz, 2007; Scheufele y Tewksbury, 2007).

Múltiples estudios han empleado la Teoría del Framing para evaluar el modo en que los medios presentan la información, seleccionando algunos aspectos de la realidad y otorgándoles mayor importancia, condicionando el entorno social, ya que la exposición a un encuadre específico, influye en las actitudes y comportamientos sobre un determinado fenómeno (Ardévol-Abreu, 2015; D’Adamo y García, 2007; Cheregui, 2015; Fryberg et al., 2012; Muñiz, 2007; Vliegenthart, 2012). Sin embargo, investigaciones anteriores han demostrado que la influencia del frame se produce en función del significado que atribuye el individuo a lo que ha visto o escuchado. Por tanto, no existe una relación directa entre la exposición al mismo y la interpretación que realiza un individuo, ya que también influyen las actitudes y valores previos 
Influencia de los periódicos españoles en la creación de estereotipos ...

que mantenga el sujeto, así como su entorno social (Ardévol-Abreu, 2015; Scheufele y Tewksbury, 2007; Vliegenthart, 2012).

Actualmente, la población tiene un mayor y más rápido acceso a la información gracias a internet. Hoy en día se producen más noticias, de diversa índole y con una gran participación de la población debido a la interacción horizontal que es facilitada por las redes sociales y los medios de comunicación, teniendo una mayor influencia a la hora de configurar tanto la agenda política (las noticias que son discutidas) como el discurso público (los contenidos sobre las noticias presentadas). De este modo, los medios influyen tanto en los problemas en los que pensamos como en el modo en que los explicamos (Cheregui, 2015; lyengar, 1994).

Debido a que la prensa contribuye al modo en el que el debate público es presentado y entendido, ayuda a conformar ciertos estereotipos y prejuicios sobre ciertos colectivos como el de los inmigrantes. La forma en que los medios encuadran la información juega un papel importante en la manera en que ciertos fenómenos políticos y sociales, como la inmigración, son presentados, así como el modo en el que la gente responde a los mismos. Por ello, resulta importante analizar cuáles son las imágenes que transmiten de ciertos colectivos de inmigrantes como los marroquíes y en qué medida refuerzan ciertos tipos de visiones estereotipadas de los mismos.

En el contexto español, los periódicos a menudo abordan la cuestión de la inmigración con titulares como los siguientes: "Detenidos dos marroquíes en Murcia y Valladolid por su relación con Daesh" (ABC, 26/9/2016); "La Gendarmería marroquí rechaza a 300 inmigrantes en la valla de Ceuta" (ABC, 22/12/2014); "Policía española y marroquí evita la entrada de 200 subsaharianos en Melilla" (El Mundo, 16/3/2014). En ellos casi nunca aparecen como actores principales, excepto cuando se les asocia a actos negativos vinculados a la violencia, a contextos de ilegalidad o a la delincuencia (Cheregui, 2015). La prensa no suele analizar las causas y el contexto de tales problemas, ni suele prestar atención a las dificultades experimentados por ciertos colectivos de inmigrantes, como consecuencia de actitudes prejuiciosas o conductas discriminativas relacionadas con sus condiciones laborales y educativas. Un tratamiento tan negativo de la inmigración, presentándose como problema social, es probable que ayude a conformar estereotipos y actitudes negativas hacia este colectivo (Fryberg et al., 2012; Sobrados, 2011; Van Dijk, 1997). 
Un ejemplo de ello lo tenemos en el estudio de Vliegenthart y Roggeband (2007) en el que dichos autores analizaron el modo en el que los medios de comunicación y el ámbito político abordaron las cuestiones relativas a la inmigración durante la última década. En ambas esferas, a raíz del atentado del 11 de septiembre de 2001 en Estados Unidos, aumentó la saliencia de las diferencias culturales entre occidentales y musulmanes, percibiéndose tales diferencias como una amenaza y principal obstáculo para la integración de los musulmanes. Cabe señalar que este discurso, sobre las diferencias entre "nosotros" y "ellos" es a menudo promovido por partidos políticos de extrema derecha (Ekman, 2015).

La situación descrita afecta de igual manera a la prensa escrita española. El estudio realizado por Igartua, Muñiz y Cheng (2005) sobre el posicionamiento de la prensa española en el tratamiento de la inmigración en tres diarios españoles: "El País", “El Mundo" y "ABC”, así lo muestra. En general, todos estos periódicos hacían referencia al mismo tipo de acontecimientos relacionados con la inmigración, pero diferían en el emplazamiento y el tipo de encuadre en función de su posicionamiento ideológico (progresista vs conservador) y su modelo de diario (prensa no sensacionalista vs sensacionalista). De este modo, el diario El País, clasificado como menos conservador y no sensacionalista, aportaba un punto de vista más complejo al tema de la inmigración, mientras que el diario "ABC", de ideología más conservadora, también desarrolla un discurso centrado en la política inmigratoria, pero vinculando la inmigración con la delincuencia. Por último, las informaciones sobre inmigración publicadas en el diario El Mundo se planteaban desde una postura ideológica menos conservadora que el "ABC", pero estaban teñidas de un mayor populismo, enfatizando la problemática social de los inmigrantes en términos más sensacionalistas.

La prensa sensacionalista y la no sensacionalista abordan, por tanto, de distinta forma la inmigración. La primera se centra en sus consecuencias económicas y la amenaza que supone para el mercado laboral la presencia de inmigrantes. La segunda enfatiza los efectos de la libre circulación, analizando las implicaciones de las políticas migratorias de la UE. Además, el ámbito de las prestaciones sociales que benefician al colectivo inmigrante está mucho más presente en la prensa sensacionalista, así como el mayor nivel de crímenes cometidos por los mismos, presentándolos como una amenaza para la seguridad de los ciudadanos (Cheregui, 2015). Por otro lado, los periódicos 
Influencia de los periódicos españoles en la creación de estereotipos ...

conservadores, en comparación con los más liberales, tienden a manejar psicológicamente el miedo y la incertidumbre, encuadrando las noticias sobre inmigración en términos de amenaza económica e inseguridad pública (Fryberg et al., 2012). De este modo, se supone que los diarios de corte sensacionalista y conservador tenderán a transmitir una imagen más negativa del colectivo inmigrante que los diarios menos sensacionalistas y liberales.

Dada la importancia que los medios de comunicación ejercen sobre los estereotipos, prejuicios y comportamientos discriminatorios que se mantienen hacia los inmigrantes, los problemas subyacentes a esta investigación son los siguientes: (1) Cómo encuadran los periódicos españoles el colectivo marroquí en España? (2) Qué discurso emplean los medios de comunicación sobre estos inmigrantes? Para ello, se compararán tres periódicos de ideología opuesta, por un lado "ABC", y por otro, "El Mundo" y, por último, "El País".

\section{Metodología}

La investigación se basa en un estudio exploratorio, de abordaje cuanti-cualitativo, apoyado en el aporte teórico de la Teoría del Framing.

\section{Recogida de datos}

Para conformar la muestra, se recopilaron todos los titulares de artículos de noticias que incluyesen la palabra "marroquí" de tres diarios nacionales "El Mundo", "ABC" y "El País", disponibles online. Se seleccionaron aquellos titulares publicados entre los años 2008 y 2016. Se estableció este período ya que en el año 2008 se produjo el inicio de la crisis económica en España, hasta 2016, período más reciente (dado que el año 2017 está en curso, no fueron añadidos los datos de este año).

\section{Análisis de datos}

Este estudio se basa en un análisis cuantitativo y cualitativo de contenido, realizado mediante el software de Análisis Textual IRAMUTEQ ya que permite realizar análisis multivariados, en concreto, la Clasificación Jerárquica Descendente (CJD) y el Análisis Factorial de Correspondencia (AFC). En total se identificaron 2650 unidades de análisis, 1203 pertenecientes al diario "El Mundo", 637 pertenecientes al diario 
"ABC" y 810 pertenecientes al periódico "El País". Por lo tanto, se generaron tres corpus de análisis.

La Clasificación Jerárquica Descendente (CJD) analizó ambos corpus en función de sus respectivos vocabularios, analizando lexicográficamente el texto. En el corpus del diario "El Mundo" se categorizaron cuatro clases; en el corpus del diario "ABC" se categorizaron tres clases; en último lugar, el corpus del diario "El País" se categorizaron cuatro clases.

En el diario "El Mundo", se observa que el corpus se divide en dos subcorpus. El primero da lugar a las clases 1 y 4 , ambas interrelacionas, las cuales hacen referencia al ámbito local e internacional respectivamente. El segundo subcorpus da lugar a las clases 2 y 3, igualmente interrelacionadas, las cuales hacen referencia al ámbito político-institucional y cultural.

Por su parte, el corpus del diario "ABC" se divide en dos subcorpus. El primero se corresponde con la clase 1, la cual hace referencia a la política migratoria. El segundo subcorpus da lugar a dos clases interrelacionadas, la clase 2 y 3 , las cuales enfatizan, respectivamente, los delitos relacionados con la pertenencia grupal de quienes los llevan a cabo y aquellos otros realizados individualmente.

En último lugar, el corpus del periódico "El País" se divide en dos subcorpus. El primero da lugar a dos clases interrelacionadas, la clase 1 y 2, las cuales hacen referencia a la pertenencia grupal. El segundo subcorpus da lugar a las clases 3 y 4 , ambas interrelacionadas, las cuales hacen referencia al ámbito de las relaciones bilaterales entre Marruecos y otros países.

A partir de la CJD, se realizó un análisis factorial de correspondencias (AFC), el cual representa en un plano cartesiano las diferentes palabras asociadas a cada una de las clases de la CJD. Este interfaz posibilita que se recuperen los segmentos de texto asociados a cada clase, obteniéndose las palabras estadísticamente significativas, posibilitando el análisis cualitativo de los datos. Además, permite un examen detallado de los vínculos existentes entre los titulares recogidos, mostrando gráficamente las relaciones entre sus diferentes contenidos representacionales. 


\section{RESULTADOS}

\section{Análisis léxico de los discursos}

Resultados de "El Mundo"

Tras la reducción de vocabulario, IRAMUTEQ originó 22,962 palabras y 463 ECU's (Unidades de Contexto Elemental). Los resultados indicaron la existencia de cuatro clases diferentes compuestas por grupos de términos representativos. La clase 1 corresponde a 35.1 por ciento (176 ECU's) de los repertorios analizados, seguida por la clase 2, representando el 25.1 por ciento (126 ECU's). Después, la clase 4 con un 21.31 por ciento (107 UCE's), y finalmente, la clase 3 originó 18.5 por ciento (93 UCE's) del total del discurso.

El análisis semántico del contenido de la clase 1, denominado "Delitos comunes diarios", mostró la existencia de un eje centrado en una representación negativa del colectivo marroquí, al asociarlo a delitos comunes como hurtos, asesinatos o violaciones. Dentro de las palabras más frecuentes se encuentran "agresión", "guardia" o "muerte", las cuales relacionan al colectivo marroquí con crímenes comunes (Figura 1). Además, cabe destacar, que esta clase fue más representativa en el $2008\left(f=206 ; \chi^{2}=9 ; p<0.001\right)$, año de inicio de la crisis económica en Europa

Los ejemplos de las UCE's de la clase 1 permiten observar cómo se representa a los marroquíes como perpetradores de crímenes que ocurren en España. (Ejemplos de UCE's del discurso léxico de la clase "Delitos comunes diarios": Tres detenidos en Valladolid por la muerte de un hombre a tiros en un ajuste de cuentas. La policía ha detenido a tres hombres con edades comprendidas entre los 23 y 27 años de nacionalidad marroquí como supuestos implicados en la muerte de un joven / Secuestro exprés con final feliz. La policía nacional ha detenido en la localidad malagueña de Estepona a dos ciudadanos de nacionalidad marroquí como presuntos autores de un secuestro exprés que se prolongó durante unas 24 horas).

El contenido semántico de la clase 2, fue denominado "Ámbito político-institucional", presenta contenidos que informan sobre las relaciones bilaterales existentes entre España y Marruecos, no transmitiendo necesariamente una visión negativa del colectivo. 
Figura 1. Clasificación de los periódicos analizados según su ideología y modelo de diario

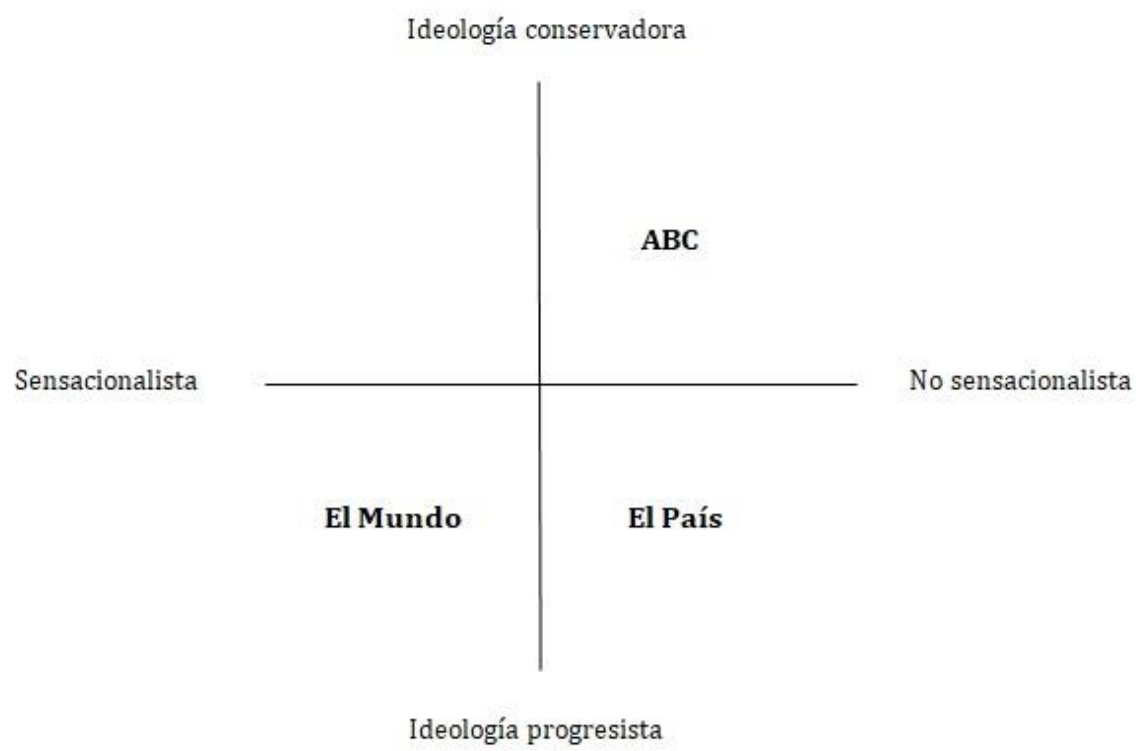

La Figura 1 muestra la frecuencia de las palabras encontradas en los discursos, donde se verifica la presencia de términos como "ministro", "Marruecos" o "gobierno".

En los discursos presentados es posible observar una descripción entre las relaciones mantenidas por ambos países con relación a temas de la política internacional. (Ejemplos de UCE's del discurso léxico de la clase "Ámbito político-institucional": La ruptura entre Rabat y París impulsa la cooperación marroquí con España al más alto nivel / Baleares y Marruecos desarrollan una plataforma conjunta para atraer inversores. La intención es que tanto la comunidad autónoma como el gobierno marroquí puedan encontrar juntos mercados internacionales).

La clase 4, denominada "Delitos internacionales" muestra por medio de la frecuencia de términos, una representación negativa del colectivo marroquí, al asociarlo a grupos islamistas o al tráfico de drogas. Siendo las palabras predominantes "hachís", "tráfico" o "islámico", en- 
tre otras. Esta clase fue más representativa en el $2016\left(f=14 ; \chi^{2}=7.07\right.$; $p<0.001$ ), año en el que se cometieron atentados terroristas en Europa (e.g. Bataclan en Francia, los atentados en el aeropuerto de Bélgica). La Figura 2 contiene todas las frecuencias de los términos encontrados en estos discursos.

Figura 2. Dendograma referente a la distribución del vocabulario de las clases según la Clasificación Jerárquica Descendente con relación al término "marroqui"

\begin{tabular}{|c|c|c|c|}
\hline Clase 1 & Clase 4 & Clase 2 & Clase 3 \\
\hline Delitos comunes diarios & Delitos internacionales & A. politico-institucional & A. Cultural \\
\hline$U C E=176$ & $\mathrm{UCE}=107$ & $\mathrm{UCE}=126$ & $U C E=93$ \\
\hline $\begin{array}{lll}\text { Término } & f & X^{2}\end{array}$ & Término $f$ & Término $f$ & Término $f$ \\
\hline $\begin{array}{lll}\text { Joven } & 50 & 53.74\end{array}$ & $\begin{array}{lll}\text { Detener } & 125 & 88.64\end{array}$ & $\begin{array}{ll}\text { Marruecos } 69 & 78.74\end{array}$ & Cine 11 \\
\hline $\begin{array}{lll}\text { Año } & 116 & 51.47\end{array}$ & $\begin{array}{lll}\text { Hachis } & 25 & 69.76\end{array}$ & Ministro 25 & Real 18 \\
\hline $\begin{array}{lll}\text { Hombre } & 45 & 28.22\end{array}$ & $\begin{array}{lll}\text { Drogar } & 15 & 47.82\end{array}$ & Gobierno $24 \quad 33.38$ & Condenar $16 \quad 34.92$ \\
\hline $\begin{array}{lll}\text { Presunto } & 37 & 25.22\end{array}$ & $\begin{array}{lll}\text { Sirio } & 12 & 45.38\end{array}$ & $\begin{array}{lll}\text { Exterior } & 9 & 27.35\end{array}$ & $\begin{array}{ll}\text { Marrakech } 6 & 26.71\end{array}$ \\
\hline $\begin{array}{lll}\text { Pequeño } & 26 & 25.16\end{array}$ & $\begin{array}{lll}\text { Islámico } & 14 & 43.95\end{array}$ & Presidente 15 & Jugar \\
\hline $\begin{array}{lll}\text { Agredir } & 12 & 22.77\end{array}$ & Operación $16 \quad 43.17$ & $\begin{array}{lll}\text { Zapatero } & 7 & 21.18\end{array}$ & Cañada 6 \\
\hline $\begin{array}{lll}\text { Fallecer } & 13 \quad 19.21\end{array}$ & $\begin{array}{lll}\text { Tráfico } & 18 & 42.82\end{array}$ & Espeleólogo $7 \quad 21.18$ & $\begin{array}{lll}\text { Nuevo } & 14 & 26.7\end{array}$ \\
\hline $\begin{array}{lll}\text { Muerte } & 15 & 18.09\end{array}$ & $\begin{array}{lll}\text { Red } & 20 & 42.77\end{array}$ & $\begin{array}{ll}56 & 20.79\end{array}$ & Pena \\
\hline $\begin{array}{lll}\text { Agresión } & 9 & 16.97\end{array}$ & $\begin{array}{lll}\text { Persona } & 32 & 40.01\end{array}$ & $\begin{array}{lll}\text { Rabat } & 21 & 20.14\end{array}$ & $\begin{array}{lll}\text { Humano } & 5 & 22.21\end{array}$ \\
\hline $35.1 \%$ & $21.3 \%$ & $25.1 \% \%$ & $18.5 \%$ \\
\hline
\end{tabular}


En los discursos de esta clase se verifica el énfasis en delitos relacionados con el terrorismo o el tráfico de drogas. (Ejemplos de UCE's del discurso léxico de la clase "Delitos internacionales": Un inspector de la policía marroquí encarcelado en Ceuta por tráfico de drogas. La guardia civil halló 185 kilos de hachís en el coche con el que cruzaba la frontera / Detenido en Polonia un marroquí residente en España que volvía tras combatir con el Estado Islámico).

La clase 3, llamada "Ámbito cultural", se centra en cuestiones relacionadas con los deportes, cine, festivales. La Figura 2, presenta los resultados de los términos encontrados.

Los extractos de los repertorios discursivos de esta clase no muestran necesariamente un estereotipo negativo del colectivo marroquí, sino las "contribuciones culturales" en los deportes y actividades artísticas. (Ejemplos de UCE's del discurso léxico de la clase "Ámbito cultural": La película rusa "Pole wild field" se alzó triunfadora del octavo festival internacional de cine de Marraquech (Marruecos) al hacerse con la estrella de oro en la gala de clausura celebrada en la ciudad marroquí. La Bienal sitúa a Marrakech en el mapa del arte / La $5^{a}$ edición de una cita artística empeñada en reformular la imagen internacional de la ciudad marroquí se celebra durante todo el mes de marzo bajo el lema "Dónde estamos?).

En conjunto, estos resultados presentan dos clases que ofrecen una visión de los marroquíes como una amenaza en términos de seguridad. La clase 1 (35.1 por ciento) vincula el colectivo marroquí con delitos comunes, mientras que la clase 4 (21.3 por ciento) asocia al colectivo marroquí con delitos del ámbito internacional.

Las relaciones espaciales de las cuatro clases discursivas fueron analizadas por medio de un Análisis de Correspondencias (Figura 3) que demuestra las dimensiones latentes que organizan estas clases. Se considera que las relaciones de proximidad y distanciamiento de estas clases pueden ser entendidas como ejes organizadores, los cuales presentan las diferentes maneras en que la prensa representa al colectivo marroquí. Esta organización está basada en la definición de los principios organizadores de las representaciones sociales (Doise, 1990).

Para analizar la manera en que estas cuatro clases organizan los repertorios discursivos de los textos del periódico "El Mundo" (Figura 3 ) se presentan los dos ejes resultantes del análisis factorial de correspondencias realizado. En el eje horizontal, en el lado derecho de la figura, se encuentran dos clases que relacionan a los marroquíes con la 
política de seguridad (clase 1 y 4). En el lado izquierdo, hay dos clases en las que los discursos revelan la asociación del colectivo marroquí a cuestiones políticas e institucionales.

Figura 3: Análisis Factorial de Correspondencias del diario "El Mundo"

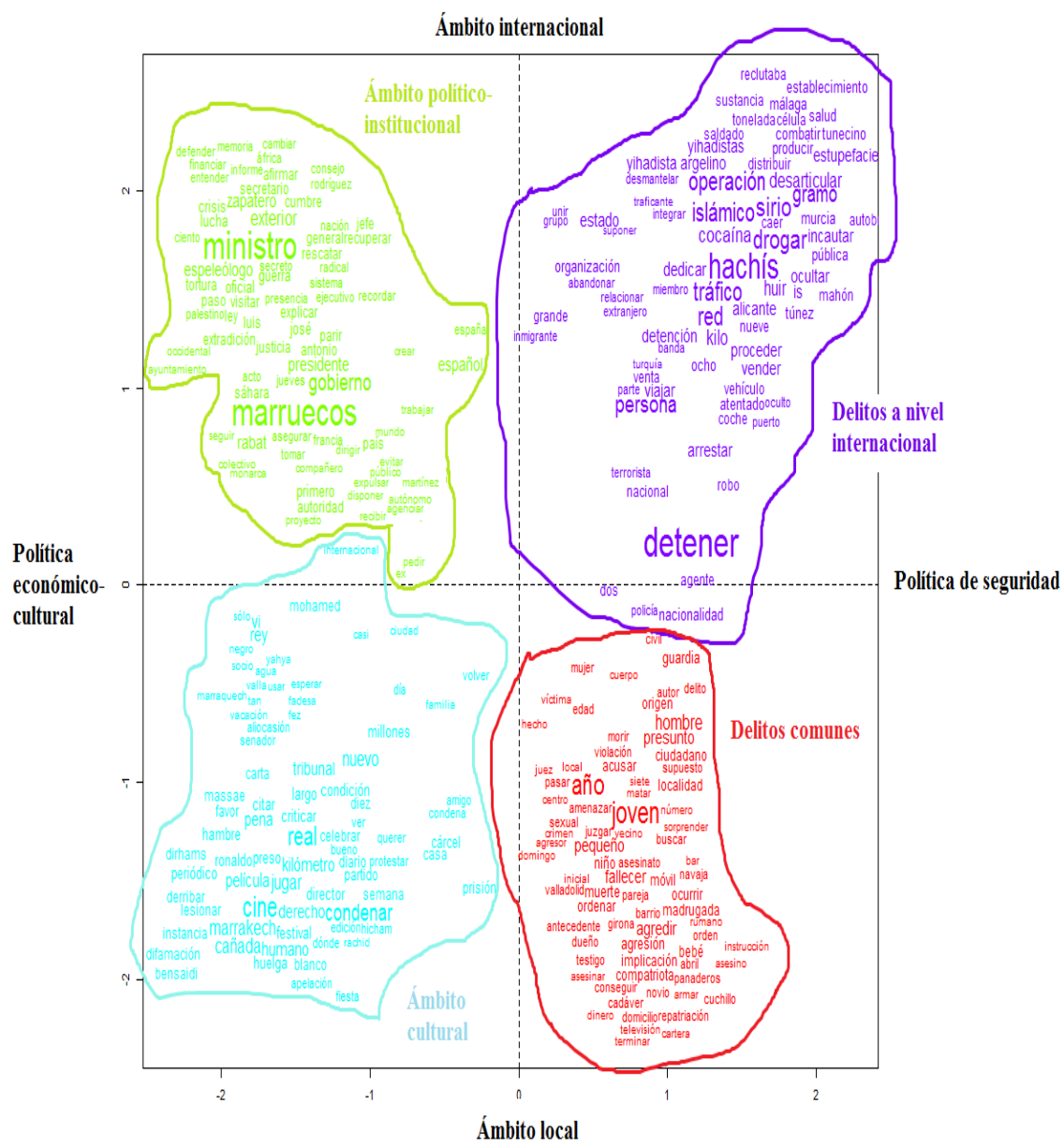


Respecto a la organización del eje vertical, se verifica que en la parte superior de la Figura 3, las clases están relacionadas con el ámbito internacional (clase 2 y 4). Las dos clases de la parte inferior de la Figura 3 presentan el colectivo marroquí asociado a cuestiones del ámbito cotidiano (clase 1 y 3 ).

En síntesis, el análisis horizontal presenta dos formas de representar a los marroquíes por el diario "El Mundo". Por un lado, dos clases que hablan de un aspecto más negativo, centrándose en la amenaza real propiamente dicha, haciendo referencia a la seguridad. Por otro lado, se observan aspectos del ámbito institucional, no necesariamente representados en términos de amenaza. En el plano vertical, los titulares incluidos presentan a los marroquíes en el ámbito de las relaciones internacionales (clase 2 y 4), en contraste con cuestiones más relacionadas al ámbito locales (clase 1 y 3 ).

Finalmente, en el periódico "El Mundo", anteriormente clasificado como sensacionalista y menos conservador que sus homólogos "la Razón" y "ABC", se observa un contraste en el que, por un lado, se asocia claramente el colectivo marroquí con una amenaza real en términos de seguridad, tanto en el ámbito local como en el ámbito de delitos internacionales. Y por otro, el colectivo marroquí se presenta relacionado con cuestiones que no necesariamente implican una percepción aspectos culturales e institucionales, con un contenido representacional más neutro.

\section{Resultados de "ABC"}

Tras la reducción de vocabulario, IRAMUTEQ originó 7637 palabras y 475 ECU's. Los resultados indicaron la existencia de tres clases diferentes compuestas por grupos de términos representativos. La clase 1 corresponde al 39.6 por ciento (166 ECU's) de los repertorios analizados, seguida de la clase 2, con un 38.7 por ciento (172 ECU's). A continuación, la clase 3 , con un 21.8 por ciento (137 UCE's).

El análisis semántico del contenido de la clase 1, denominado "Control del flujo migratorio", mostró la existencia de un eje centrado en una representación negativa del colectivo marroquí, al percibirse como un problema o amenaza el paso de inmigrantes a través de la frontera. Dentro de las palabras más frecuentes se encuentran "Melilla", "Ceuta" o "frontera" (Figura 4). Cabe destacar que esta clase fue más representativa en el $2010\left(f=34 ; \chi^{2}=17.38 ; p<.0001\right)$, año en el que se intensificaron los debates políticos en torno a los musulmanes y 
la prohibición del velo islámico en los espacios públicos, comenzando a percibirse la inmigración más como una amenaza cultural que económica-laboral (Cea D’Ancona, 2017).

Figura 4. Dendograma referente a la distribución del vocabulario de las clases según la Clasificación Jerárquica Descendente con relación al término "marroqui"

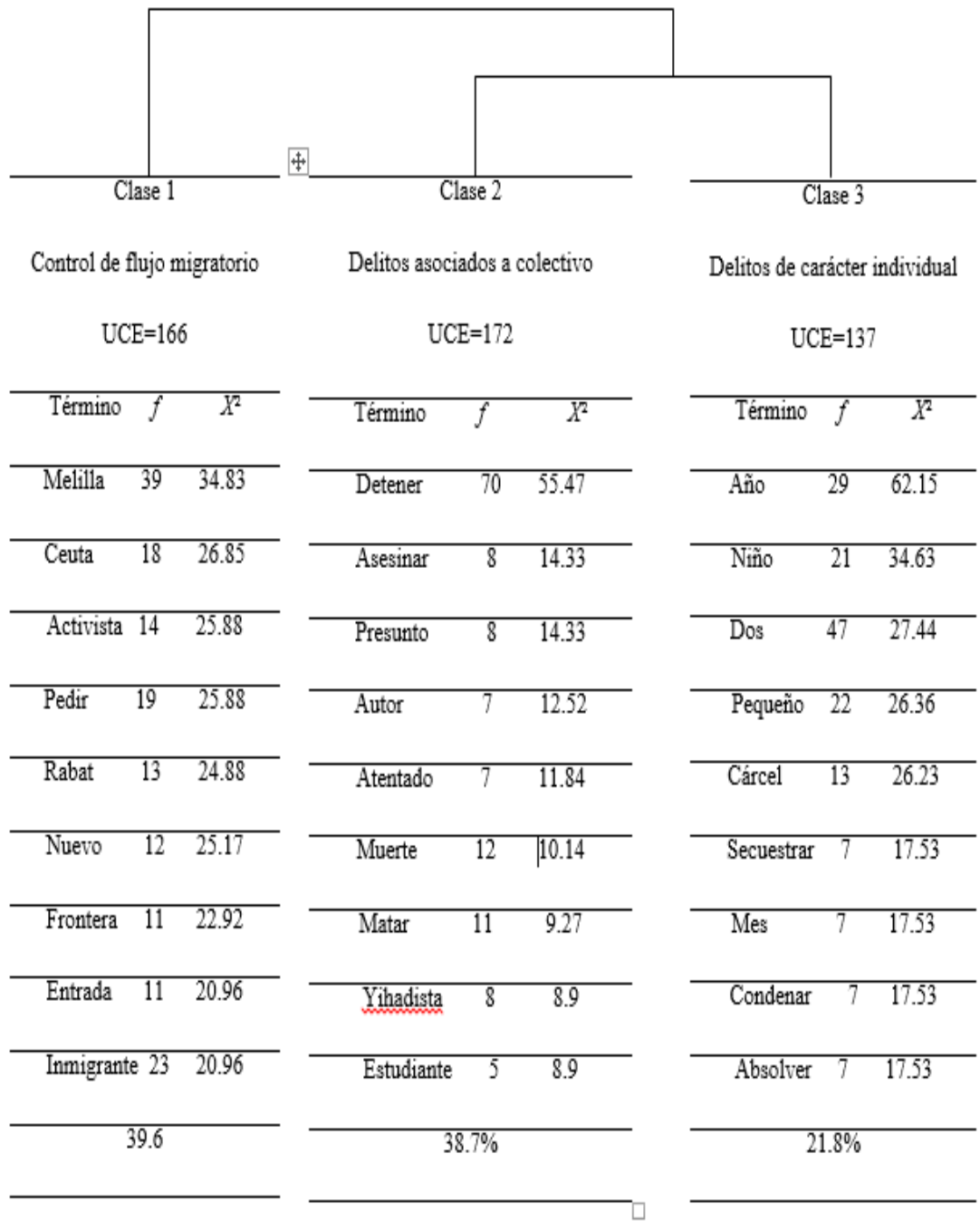


Como ejemplos de UCE's de la clase 1. Se observó que los titulares analizados vinculan a los marroquíes con una amenaza, dado que se concibe la inmigración ilegal de este colectivo como un problema social para el país. (Ejemplos de UCE's del discurso léxico de la clase "Control del flujo migratorio": La gendarmería marroquí rechaza a 300 inmigrantes en la valla de Ceuta / Policía marroquí detiene a 44 subsaharianos que trataban de entrar en España).

El contenido semántico de la clase 2, nombrado "Delitos asociados a un colectivo", vuelve a presentar una visión negativa del colectivo marroquí, asociando a la práctica de actos delictivos, por ejemplo, a la pertenencia a grupos yihadistas y contrabandistas. La Figura 4 muestra la frecuencia de las palabras encontradas en el discurso, donde verificamos la presencia de términos como "detener", "asesinar" o "presunto".

En los discursos presentados es posible observar esa tendencia a asociar al colectivo marroquí con determinados grupos delictivos. (Ejemplos de UCE's del discurso léxico de la clase: "Delitos asociados a un colectivo": Comienza el macrojuicio a una banda marroquí por robar placas solares / Detenido un marroquí en Las Palmas acusado de captar menores para el terrorismo islamista).

La clase 3, nombrada "Delitos de carácter individual" ofrece, nuevamente, una visión negativa del colectivo marroquí, pero haciendo referencia al sistema de justicia y cómo éste responde a los actos delictivos cometidos por este grupo. Siendo las palabras predominantes "cárcel", "secuestrar" o "condenar". La Figura 4 contiene todas las frecuencias de términos hallados en estos discursos.

En los discursos de esta clase, se verifica está visión negativa del colectivo marroquí. (Ejemplos de UCE's del discurso léxico de la clase "Delitos de carácter individual": Condenado a muerte un marroquí que raptó, violó y mató a una niña de dos años / Juzgan a ocho policías marroquíes implicados en el tráfico de inmigrantes).

Los resultados presentan las tres clases que ofrecen una visión de los marroquíes como una amenaza a la seguridad del país. La clase 1 concibe a este colectivo como causa principal del problema de la inmigración ilegal, la clase 2 , por su parte, asocia este colectivo a grupos que cometen actos delictivos. Finalmente, la clase 3, pone su foco en los actos delictivos cometidos individualmente por miembros de este grupo, y en cómo reacciona el sistema de justicia ante los mismos. 
Las relaciones espaciales de las tres clases discursivas fueron analizadas por medio de un Análisis de Correspondencias (Figura 5) que demuestra las dimensiones latentes que organizan estas clases en términos de relaciones de proximidad y distanciamiento.

Figura 5: Análisis Factorial de Correspondencias asociado al diario "ABC"

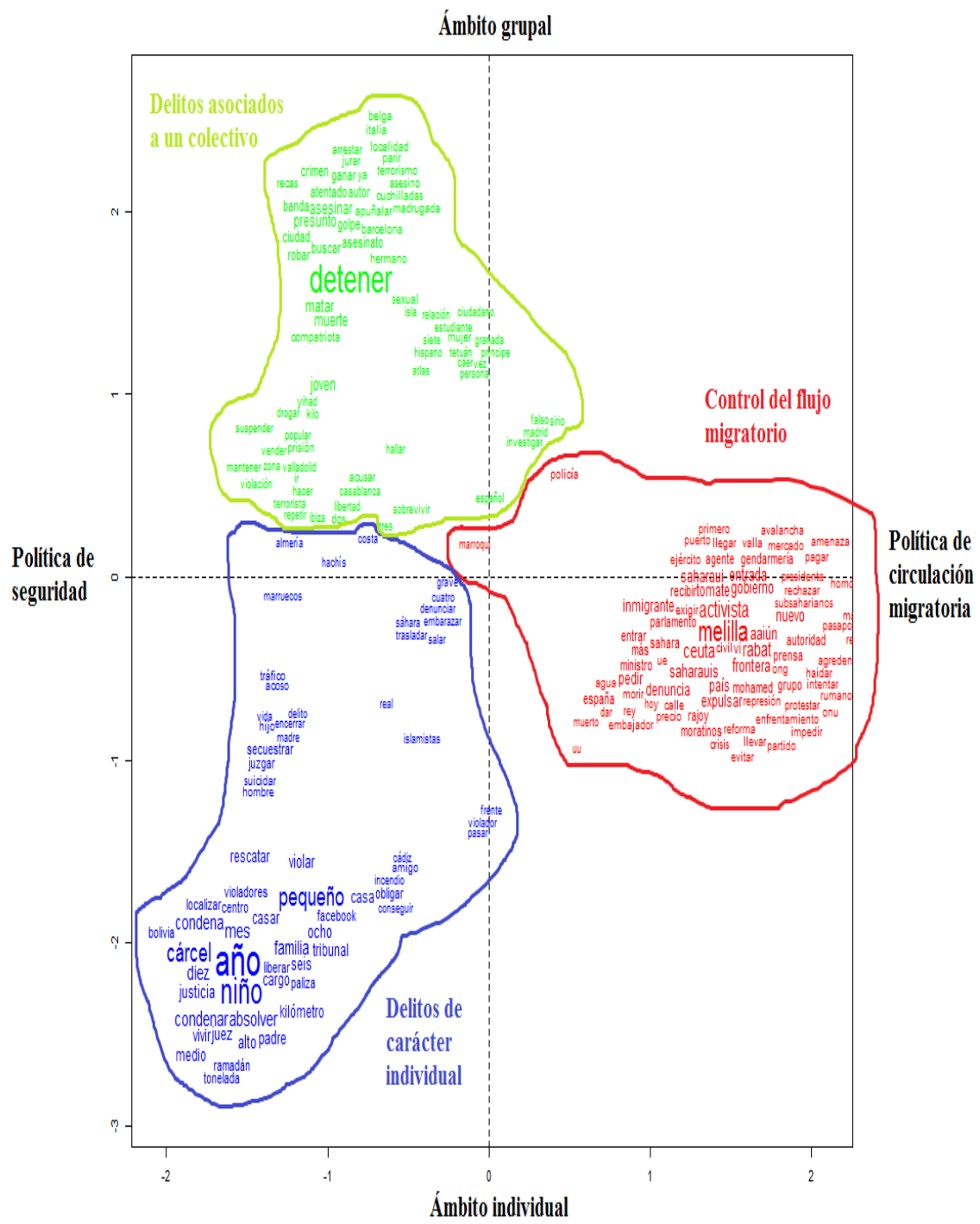


Para analizar el modo en que estas cuatro clases organizan los repertorios discursivos de los títulos del diario "ABC" (Figura 5) se presenta la discusión de los dos ejes (horizontal y vertical) resultado del análisis factorial de correspondencias. En el eje horizontal, en el lado derecho de la figura encontramos la clase 1 que relaciona a los marroquíes con la política migratoria. En el lado izquierdo, hay dos clases que relacionan a los marroquíes con la política de seguridad (clase 2 y 3).

Respecto a la organización del eje vertical, se observa que en la parte superior de la Figura 5 se encuentra una clase relacionada con la pertenencia grupal del colectivo de marroquíes, asociada a la inmigración ilegal. En la parte de abajo, se encuentran dos clases que reflejan actos cometidos individualmente, una centrada en actos delictivos (clase 3) y otra enfatizando los múltiples intentos de atravesar ilegalmente la frontera de Ceuta y Melilla (clase 1).

En síntesis, observamos claramente una representación negativa del colectivo marroquí, al transmitir una percepción de amenaza, tanto a nivel grupal como individual.

De este modo, el diario "ABC", anteriormente clasificado como no sensacionalista y conservador (Igartua et al., 2005, asocia claramente al colectivo marroquí a una amenaza real en términos de seguridad, tanto en delitos de carácter individual como grupal. Además, este diario presenta una clase específica sobre el problema de la inmigración, presentando a los marroquíes como causa de esta problemática.

\section{Resultados del diario "El País"}

Tras la reducción de vocabulario, IRAMUTEQ originó 27.260 palabras y 638 ECU's. Los resultados indicaron la existencia de cuatro clases diferentes compuestas por grupos de términos representativos. La clase 1 corresponde a 22.57 por ciento (144 ECU's) de los repertorios analizados, seguida de la clase 2, con 16.61 por ciento (106 ECU's). A continuación, la clase 3, con 34.64 por ciento (221 UCE's). Finalmente, la clase 4, con 26.18 por ciento (167 ECU's).

El análisis de contenido de la clase 3, denominado "Ámbito político-migratorio", mostró la existencia de un eje centrado en una representación negativa del colectivo marroquí, al presentar la inmigración como un problema social. Dentro de las palabras más frecuentes se encuentran "exterior", "Ministro" o "Aaiún" (Figura 6). Además, esta clase fue más representativa en el $2010\left(f=61 ; \chi^{2}=20.99 ; p<0.001\right)$, año en 
el que, como se ha comentado anteriormente, se comienza a percibir la inmigración más como amenaza cultural que económica (Cea D’Ancona, 2017).

Figura 6. Dendograma referente a la distribución del vocabulario de las clases según la Clasificación Jerárquica Descendente con relación al término "marroqui"

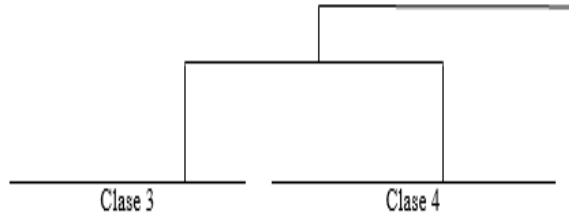

A. Politico-migratorio

$\mathrm{UCE}=221$

\begin{tabular}{|c|c|}
\hline Término $f \quad x^{2}$ & Término $f$ \\
\hline $\begin{array}{lll}\text { Ministro } & 45 & 53.04\end{array}$ & Mohamed VI $125 \quad 88.64$ \\
\hline $\begin{array}{lll}\text { Exterior } & 25 & 43.27\end{array}$ & $25 \quad 69.76$ \\
\hline $\begin{array}{lll}\text { Aaiun } & 28 & 38.63\end{array}$ & $\begin{array}{lll}\text { Islamista } & 15 & 47.82\end{array}$ \\
\hline Activista $26 \quad 34.68$ & $12 \quad 45.38$ \\
\hline $\begin{array}{lll}\text { Frontera } & 18 & 29.26\end{array}$ & $\begin{array}{lll}\text { Municipal } & 14 & 43.95\end{array}$ \\
\hline $\begin{array}{lll}\text { Gobierno } & 53 & 25.17\end{array}$ & $\begin{array}{ll}16 & 43.17\end{array}$ \\
\hline $\begin{array}{lll}\text { Rabat } & 46 & 23.49\end{array}$ & $\begin{array}{ll}18 & 42.82\end{array}$ \\
\hline $\begin{array}{lll}\text { Reunir } & 15 & 23.37\end{array}$ & $\begin{array}{lll}\text { Desarrollo } & 20 & 42.77\end{array}$ \\
\hline $\begin{array}{lll}\text { Haidar } & 15 & 23.37\end{array}$ & $32 \quad 40.01$ \\
\hline $34.64 \%$ & $26.18 \%$ \\
\hline
\end{tabular}



Delitos comunes

UCE $=144$
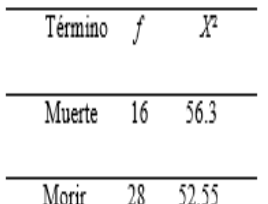

$\begin{array}{lll}\text { Detener } & 100 & 161.12\end{array}$

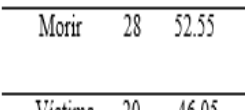

\begin{tabular}{lll}
\hline Arrestar & 24 & 112.97
\end{tabular}
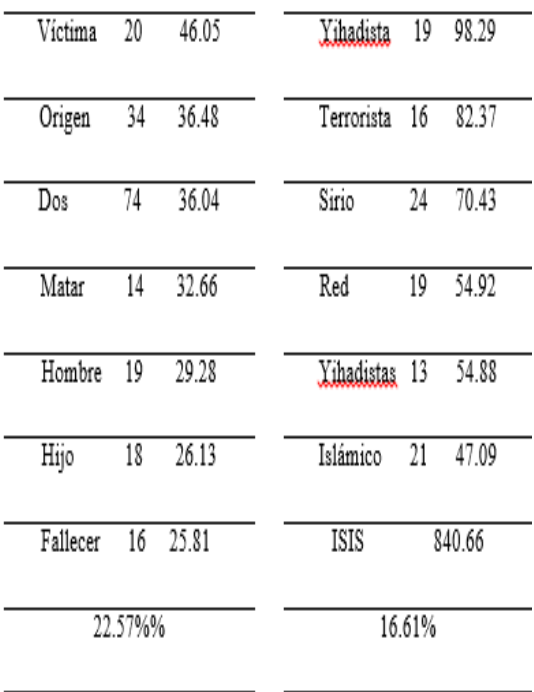
Ejemplos de UCE's del discurso léxico de la clase "Ámbito político-migratorio": El cerrojazo de marruecos desvía la inmigración hacia Libia, miles de sin papeles han sido desplazados a ciudades del sur marroquí, otros intentan regresar a sus países y muchos prueban suerte en el litoral libio. / La élite de los porteadores de Melilla. Un centenar de vigilantes marroquíes controlan el flujo de los miles de compatriotas que transportan paquetes en la frontera.

El análisis semántico de la clase 4, denominada "Ámbito políticoinstitucional", no transmite necesariamente una imagen negativa de este colectivo, ya que informa sobre las relaciones bilaterales entre Marruecos y otros países, incluyendo temas como economía y política antiterrorista. La Figura 6 muestra las palabras más representativas de esta clase, donde encontramos "Mohamed VI", "Islamista" o "Municipal".

Ejemplos de UCE's del discurso léxico de la clase "Ámbito políticoinstitucional": Susana Díaz afianza su perfil internacional ante Marruecos 150 empresarios marroquíes y andaluces estrechan relaciones comerciales en Sevilla / Hollande y Mohamed VII firman un nuevo pacto antiterrorista, ambos mandatarios ponen fin en París al bloqueo en la colaboración policial. La crisis surgió tras un proceso contra el jefe del espionaje marroquí.

En el análisis semántico de la clase 1, nombrada "Delitos comunes", se observa la existencia de un eje que transmite una imagen negativa del colectivo marroquí, al asociarlo a delitos cotidianos como asesinatos o violaciones. Dentro de las palabras más representativas de esta clase encontramos "muerte", "morir" o "víctima" (Figura 6).

En los discursos de esta clase, se verifica esta visión negativa del colectivo marroquí. (Ejemplos de UCE's del discurso léxico de la clase "Delitos comunes": Detenidas seis personas que robaban viviendas por el método bumping, seis personas cuatro hombres y dos mujeres de nacionalidad marroquí han sido detenidas por asaltar tres casas en la sierra / Detenido un boxeador marroquí por abusar de dos empleadas en la villa olímpica. Hassan Saada de 22 años está ya en prisión, es el segundo caso de abuso en instalaciones olímpicas en una semana).

Finalmente, el análisis semántico de la clase 2, denominado "Delitos asociados al terrorismo", mostró una clara representación negativa de este colectivo, al asociarlo a grupos criminales de tipo terrorista, cuyas palabras predominantes fueron "Detener", "Arrestar" o "Yihadista" (Figura 6). Además, cabe destacar que esta clase fue más representativa los años $2014\left(f=18 ; \chi^{2}=10.12 ; p<0.001\right), 2016\left(f=16 ; \chi^{2}=7.69\right.$; 
Influencia de los periódicos españoles en la creación de estereotipos ...

$p<0.005)$ y $2015\left(f=22 ; \chi^{2}=6.08 ; p<0.013\right)$, pudiendo estar relacionado con la perpetración de los atentados terroristas en Europa.

Ejemplos de UCE's del discurso léxico de la clase "Delitos asociados al terrorismo": Prisión para los dos hermanos marroquíes por pertenecer y financiar al Estado Islámico; el juez establece que los dos jóvenes arrestados en Arbúcies remitían dinero al Estado Islámico / Un detenido en Valencia por enaltecimiento yihadista; la policía arresta a un ciudadano marroquí que mantenía contactos con mandos del Estado Islámico.

En conjunto, estos resultados muestran tres clases que representan a los marroquíes como una amenaza en términos de seguridad. La clase 3, vincula al colectivo marroquí al problema social de la inmigración; la clase 1 a los marroquíes con delitos comunes y la clase 2 a delitos asociados al terrorismo.

Para analizar el modo en que estas cuatro clases organizan los repertorios discursivos de los títulos del diario "El País" (Figura 7) se presenta la discusión del eje horizontal. En el lado derecho de la figura se encuentran dos clases que enfatizan la pertenencia de los marroquíes a grupos yihadistas o a otros grupos delictivos (Clases 1 y 2). Por su parte, las dos clases del lado izquierdo enfatizan las relaciones bilaterales entre países.

Respecto a la organización del eje vertical, se observa que en la parte superior de la Figura 7, las clases están relacionadas con cuestiones de la política externa, cuestiones de seguridad (clase 1) y acuerdos políticos y económicos (Clase 4). Por otro lado, las clases de la parte inferior de la Figura 3, asocian el colectivo marroquí con desavenencias políticas entre países, tales como el yihadismo (Clase 2) y la inmigración ilegal (Clase 3).

Por lo tanto, el diario "El País", anteriormente clasificado como "progresista" y "no sensacionalista", presenta tres clases en las que los marroquíes son percibidos, en gran medida, negativamente, al transmitir una percepción de amenaza, asociándolos a delitos tanto de carácter cotidiano como internacional (terrorismo), además de representar la inmigración como un problema social. Cabe destacar también que los contenidos incluidos en la clase 4 no transmiten necesariamente una imagen negativa de este colectivo, al abarcar asuntos de carácter político-institucional. 
Figura 7. Análisis Factorial de Correspondencias asociado al diario "El País"






\section{Discusión}

El objetivo de esta investigación fue analizar los discursos que los principales periódicos españoles utilizan para representar al colectivo marroquí en España. Para ello se seleccionaron tres de los diarios, de diversa ideología, más leídos en España, ("El País", "El Mundo" y “ABC”) (Igartua et al., 2005). Se realizó un estudio de carácter cuantitativo, analizando los titulares de las noticias que incluyen el término "marroquí" entre los años 2008 (año de inicio de la crisis) y 2016 (período más reciente finalizado).

En el periódico "El Mundo", de carácter sensacionalista y menos conservador (Igartua et al., 2005) se observan dos representaciones del colectivo marroquí. Por un lado, se asocia con una amenaza real en términos de seguridad, tanto en el ámbito local como en el ámbito a nivel internacional. Los discursos donde se da está representación negativa del colectivo marroquí están más presentes en los años 2008 y 2016, años de inicio de la crisis y comisión de atentados en Europa por parte de grupos yihadistas. Por otro lado, este colectivo también se relaciona con cuestiones que no necesariamente implican una percepción de amenaza, tales como temas del ámbito cultural e institucional.

El diario "ABC", anteriormente clasificado como no sensacionalista y conservador (Igartua et al., 2005), presenta claramente al colectivo marroquí como una amenaza real en términos de seguridad, tanto en delitos de carácter individual como grupal. Además, en este diario se observa una clase que representa la inmigración como un problema social, presentando a los marroquíes como causa de esta problemática. Esta clase sobresale en el año 2010, año en el que se comienza a percibir la inmigración como una amenaza simbólica más que económicolaboral (Cea D'Ancona, 2017).

El diario "El País", a su vez, clasificado como "progresista" y "no sensacionalista" (Igartua et al., 2005), presenta tres clases en las que los marroquíes son asociados a problemas negativos, transmitiendo una percepción de amenaza, asociándolos a delitos tanto de carácter cotidiano (hurtos, asesinatos, acoso sexual) como internacional (terrorismo). Además, al igual que el diario " $\mathrm{ABC}$ ", asocia a los marroquíes a cuestiones relacionadas con la inmigración ilegal. Sin embargo, cabe destacar, que existe una última cuarta clase que no transmite necesariamente una imagen negativa de este colectivo, abarcando asuntos de carácter político-institucional. 
Observamos cómo en los tres periódicos analizados, predominan clases que transmiten una imagen negativa del colectivo marroquí. Sin embargo, en el diario "El Mundo" y "El País", ambos de carácter progresista, también aparecen clases que no transmiten una percepción necesariamente negativa de este grupo. En cambio, en el periódico "ABC" todas las clases encontradas difunden una imagen negativa de los marroquíes. Estos resultados son consonantes con otros estudios anteriormente realizados que señalan que las ideas progresistas tienden a ser más favorables a la inmigración, mientras que las más conservadoras tienden a dar una cobertura más negativa de este fenómeno (Artiles, Molina y Meardi, 2011; Balanova y Balch, 2010; Cheregui, 2015; Ward, Szabo y Stuart, 2016).

En el presente estudio se verificó que las clases en las que los marroquíes son más negativamente representados coinciden con períodos en los que han acaecido sucesos notables (e. g., crisis, atentados terroristas, "oleadas" de inmigración ilegal) que han ayudado a moldear la opinión pública. Se observa cómo el contexto social puede influir en la creación de estereotipos hacia un determinado colectivo. Estos estereotipos no son estables en el tiempo, si no que varían en función del contexto social y condiciones de vida de la población autóctona (Artiles, Molina y Meardi, 2011; Cea D’Ancona, 2009b; Cea D'Ancona, 2015; Ward, Szabo y Stuart, 2016).

Las consecuencias de la crisis que ha afectado Europa en 2008, en forma de recortes presupuestarios y disminución del acceso a los recursos, podrían haber influido en el refuerzo de estereotipos y actitudes negativas hacia los inmigrantes. Meuleman, Davidov y Billiet (2009) hallaron en sus estudios que un largo influjo de inmigrantes en un corto período de tiempo y altos niveles de desempleo son los mejores predictores de sentimientos anti-inmigrantes. En los países en los que el desempleo es altamente persistente, la inmigración es a menudo percibida como una amenaza económica por el incremento de la competencia percibida por los recursos. El estrés por los recursos en presencia de otros grupos relevantes y distintos aumenta la competitividad intergrupal, motivada por la escasez, acceso desigual y deseo de un desigual reparto de los recursos, influenciando la evolución de las actitudes negativas intergrupales (Artiles, Molina y Meardi, 2011; Cea D’Ancona, 2009b; Cea D’Ancona, 2015; Ward, Szabo y Stuart, 2016; Tajfel, 1981). 
Influencia de los periódicos españoles en la creación de estereotipos ...

Los discursos negativos hacia el colectivo marroquí hallados en esta investigación, en especial en los años 2008 y 2010, los períodos de inicio de la crisis económica y aumento del sentimiento anti-musulmán, respectivamente (Cea D’Ancona, 2015), corroboran los estudios llevados a cabo por Stephan y sus colaboradores (2005) que sugieren que una de las razones de la hostilidad hacia grupos de inmigrantes puede ser explicada por sentimientos de amenaza (tanto económica-laboral como cultural). El aumento del sentimiento anti-musulmán, podría estar relacionado con las clases halladas en los diarios "ABC" y "El País", ya que vinculan a los marroquíes con la inmigración ilegal, transmitiendo la imagen de que son los causantes de este problema social, siendo más representativas en el año 2010. Estos hallazgos son consistentes con diversas investigaciones realizadas en el ámbito de las relaciones intergrupales (Cea D'Ancona, 2009b; Cea D'Ancona, 2015; Ward, Szabo y Stuart, 2016).

En los diarios analizados, se pueden observar una serie de clases que presentan a los marroquíes como causantes de actos delictivos, transmitiendo una imagen negativa que provoca un sentimiento de amenaza a la seguridad. Se comprende que esta manera de encuadrar a los marroquíes ayuda a acentuar la diferencia entre "ellos" y "nosotros", asociando el "exogrupo" a aspectos negativos. Esta tendencia a destacar los sucesos más alarmantes, en términos de criminalidad y amenaza terrorista, destacando su nacionalidad marroquí (como muestran la mayoría de los titulares), criminaliza a todo el conjunto inmigrante enfatizando una naturaleza intrínsecamente violenta (Cea D’Ancona, 2009b; Enkman, 2015).

En conclusión, los datos evidencian que la prensa difunde una imagen negativa sobre el colectivo marroquí. Esta visión negativa, unida a un contexto social de crisis en el que predomina la competitividad por los recursos y la incertidumbre social, podría contribuir a crear estereotipos y prejuicios contra este colectivo, así como su consideración como problema social.

\section{Limitaciones y direcciones futuras}

Como posibles limitaciones de la presente investigación, cabe señalar que solamente se han analizado los títulos de las noticias. Es posible que, aunque en los títulos no aparezca el término "marroquí", el cuerpo de la noticia transmita una imagen negativa de este colectivo. 
En esta investigación se verificó que los tres diarios analizados presentan una visión negativa de los marroquíes. Sin embargo, no fue posible informar cómo afecta esta imagen negativa a la formación de actitudes y conductas ante este colectivo. No obstante, investigaciones anteriores han demostrado cómo la percepción de los inmigrantes en términos de amenaza aumenta el sentimiento anti-inmigrante, actitudes hostiles y conductas negativas (Ward, Szabo y Stuart, 2016; Cea D'Ancona, 2009b). Estudios posteriores podrían analizar cómo este tipo de framing influye en las actitudes y conductas frente a los inmigrantes marroquíes. En esta línea, también resultaría interesante analizar el impacto que tiene en las actitudes y conductas hacia este colectivo, la difusión de titulares que transmiten una imagen positiva de los mismos o no necesariamente negativa, como "Mil maneras de recordar Marruecos. La exposición 'Expectativa y memoria' narra, desde la fotografía, la relación entre la cultura española y la marroquí" (El País, 8/4/2016) o "Dos familias marroquíes piden entrar en prisión por falta de recursos para vivir" (ABC, 5/12/2014).

En el presente estudio no se han evaluado los comentarios online de los participantes en las noticias seleccionadas en la prensa transmitida en Internet. En este espacio se produce una mayor difusión de discursos racistas y xenófobos, ya que Internet permite una mayor participación del público al que llega la información (Cheregui, 2015; Ekman, 2015). Futuras investigaciones podrían evaluar los comentarios y discusiones que dichas noticias generan.

Finalmente, como el proceso de framing está mediado por los valores y actitudes del individuo, así como su entorno social (Ardévol-Abreu, 2015) resultaría interesante analizar cómo estos procesos podrían influir en el impacto que ejerce la exposición a un determinado frame y, a su vez, como este influye en las relaciones sociales.

\section{REFERENCIAS BIBLIOGRÁFICAS}

Allport, Gordon (1954). The Nature of Prejudice. Cambridge, MA: Addison-Wesley

Appel, Markus (2012). "Anti-Immigrant propaganda by radical rights parties and the intelectual performance of adolescents". Political Psychology, 33(4): 483- 493. Consultado el 16 de Noviembre de 2016, disponible en doi: 10.1111/j.1467-9221.2012.00902.x.

Ardévol-Abreu, Alberto (2015). "Framing o teoría del encuadre en comunicación. Orígenes, desarrollo y panorama actual en España”. Revista La- 
Influencia de los periódicos españoles en la creación de estereotipos ...

tina de Comunicación Social, 70: 423-450. Consultado el 16 de noviembre de 2016, disponible en doi: 10.4185/RLCS-2015-1053

Artiles, Martín; Molina, Óscar y Meardi, Guglielmo (2011). "Incertidumbre socioeconómica y actitudes hacia la inmigración en Europa". Cuadernos de Relaciones Laborales, 31(1): 167-194. Consultado el 15 de noviembre de 2016, disponible en doi: http://dx.doi.org/10.5209/rev_CRLA.2013.v31. n1.41645

Balanova, Ekaterina y Balch, Alex (2010). "Sending and receiving: The ethical framing of intra-EU migration in the European press". European Journal of Communication, 25(4): 382-397. Consultado el 17 de noviembre de 2016, disponible en DOI: 10.1177/0267323110381005

Basabe, Nekane y Bobowik, Magdalena (2013). "Estatus grupal, discriminación y adaptación en inmigrantes latinoamericanos y africanos en España". Psicoperspectivas, 12(1): 5-29. Consultado el 16 de noviembre de 2016, disponible en doi: 10.5027/PSICOPERSPECTIVAS-VOL12-ISSUE1-FULLTEXT-237

Bateson, Gregory (1955). A theory of play and fantasy. Psychiatric research reports.

Camino, Leoncio et al. (2013). "Explaining social discrimination: Racism in Brazil and Xenophobia in Spain". The Spanish journal of psychology, 16(73): 1-13. Consultado el 16 de Noviembre de 2016, disponible en doi: $10.1017 /$ sjp.2013.65

Cea D’Ancona, M. A. (2009a). "La compleja detección del racismo y la xenofobia a través de encuesta. Un paso adelante en su medición". En Revista Española de Investigaciones Sociológicas, 125, 13-45.

Cea D'Ancona, Ma Ángeles (2009b). “Filias y fobias ante la imagen poliédrica cambiante de la inmigración: Claves en la comprensión del racismo y la xenofobia." Revista del Ministerio de Trabajo e Inmigración 8: 39-60.

Cea D’Ancona, Ma Ángeles (2015). "Los efectos de la crisis económica en la molduración y evolución de la opinión pública española ante la inmigración". MIGRACIONES, 37: 29-52. Consultado el 10 de Diciembre de 2016, disponible en doi: mig.i37.y2015.002

Cea D’Ancona, Ma Ángeles (2017). “Percepción social de las migraciones en España." Panorama Social 24: 129-144.

Cea D’Ancona, Ma Ángeles y Valles, Miguel (2014). Evolución del racismo, la xenofobia y otras formas conexas de intolerancia en España [Informe-Encuesta 2014]. Consultado el 10 de diciembre de 2016, disponible en http://publicacionesoficiales.boe.es

CIS (2014). Actitudes hacia la inmigración (Estudio no 3019) l, Centro de Investigaciones Sociológicas, Madrid. 
Cheregui, Bianca-Florentina (2015). "The media construction of anti-immigration positions: the discourse on the romanian immigrants in the british press". Revista romana de sociologie, 26 (3-4):279-298.

D’Adamo, Orlando y García, Virginia (2007). "Medios de comunicación de masas y percepción social de la inseguridad". Boletín de Psicología, 90: 1932.

Doise, Willem (1990). "Les représentations socials". En J. F. Richard et al. (eds.), Traité de psychologie cognitive 3: Cognition, représentation, communication. Paris, France: Dunod.

Dovidio, John et al. (2010). "Prejudice, stereotyping and discrimination: theoretical and empirical overview". The SAGE handbook of prejudice, stereotyping and discrimination 3-29.

Durán, Javier \& Jiménez, Pedro (2006). "Soccer and Racism: a scientific and social problema". En International Journal of Sport Sciencie, 3, 68-94. (doi:10.5232/ricyde2006.00305)

Ekman, Mattias (2015). "Online Islamophobia and the politics of fear: manufacturing the Green scare". Ethnic and Racial Studies, 31(11): 19862002. Consultado el 30 de enero de 2017, disponible en doi:10.1080/014 19870.2015.1021264

Entman, Robert (1993). "Framing: toward clarification of a fractured paradigm". Journal of Communication, 43(4): 51-58. Consultado el 10 de Diciembre de 2016, disponible en doi: 10.1111/j.1460-2466.1993. tb01304.x

Fryberg, Stephanie et al. (2012). "How the Media Frames the Immigration Debate: The Critical Role of Location and Politics". Analyses of Social Issues and Public Policy, 12: 96-112. Consultado el 30 de Enero de 2017, disponible en doi: 10.1111/j.1530-2415.2011.01259.x

Goffman, Erving (1974). Frame analysis: an essay on the organization of experience. Nueva York: Harper and Row.

Igartua, Juan José; Muñiz, Carlos y Cheng, Lifen (2005). "La inmigración en la prensa española. Aportaciones empíricas y metodológicas desde la teoría del encuadre noticioso". Migraciones, 17: 143-181.

Iyengar, Shanto (1994). “Television news and citizen' explanation of national affairs". En D. Graber (ed.), Media power in politics (pp. 139-149). Washington: Congressional Quarterly.

López-Rodríguez, Lucía; Cuadrado, Isabel y Navas, Marisol (2013). “Aplicación extendida del Modelo del Contenido de los Estereotipos (MCE) hacia tres grupos de inmigrantes en España". Estudios de Psicología, 34(2): 197-208. Consultado el 15 de Noviembre de 2016, disponible en doi: http://dx.doi.org/10.1174/021093913806751375

Meuleman, Bart; Davidov, Eldad y Billiet, Jaak (2009). “Changing attitudes toward immigration in Europe, 2002-2007: A dynamic group conflict the- 
Influencia de los periódicos españoles en la creación de estereotipos ...

ory approach". Social Science Research, 38(2): 352-365. Consultado el 30 de enero de 2017, disponible en doi: 10.1016/j.ssresearch.2008.09.006

Molero, Fernando; Navas, Marisol y Morales, Francisco (2001). "Inmigración, prejuicio y exclusión social: reflexiones en torno a algunos datos de la realidad española". En Revista Internacional de Psicología y Terapia Psicológica, 1(1), 11-32.

Muñiz, Carlos (2007). Encuadres noticiosos e inmigración: del análisis de los contenidos al estudio de los efectos mediáticos (Tesis doctoral). Universidad de Salamanca, España.

Roggeband, C. \& Vliegenthart, R. (2007). "Divergent framing: The public debate on migration in the Dutch parliament and media, 1995-2004". En West European Politics, 30(3), 524-548.

Sádaba, Ma Teresa (2001). "Origen, aplicación y límites de la 'teoría del encuadre' (framing) en comunicación". Comunicación y Sociedad, 14(2): 143-175. Consultado el 10 de diciembre de 2016, disponible en http:// hdl.handle.net/10171/7975

Scheufele, Dietram y Tewksbury, David (2007). "Framing, agenda setting, and priming: The evolution of three media effects models". Journal of communication, 57(1): 9-20. Consultado el 10 de Diciembre de 2016, disponible en doi: 10.1111/j.0021-9916.2007.00326.x

Serrano, Ma Dolores (2014). "Exclusión social y criminalidad". Revista de Derecho, UNED 14: 587-617.

Sobrados, Maritza (2011). "La inmigración como problema. Percepciones sociales y representaciones mediáticas". Prismasocial: revista de ciencias sociales, 6: 26. Consultado el 30 de enero de 2017, disponible en http:// www.redalyc.org/articulo.oa?id $=353744578016$

Stephan, Walter et al. (2005). "The effects of feeling threatened on attitudes toward immigrants". International Journal of Intercultural Relations, 29(1): 1-19. Consultado el 30 de Enero de 2017, disponible en doi: 10.1016/j.ijintrel.2005.04.011

Stephan, Walter y Stephan, Cookie. (2000) "An integrated threat theory of prejudice". En S. Oskamp (ed.), Reducing prejudice and discrimination. New Jersey: Laurence Erlbaum

Tajfel, Henri (1981). Human groups and social categories. Cambridge University Press

Tezanos, José Félix y Tezanos, Sergio (2006). "La cuestión migratoria en España. Tendencias en inmigración y exclusión social”. Sistema, 190: 9-40.

Van Dijk, Teun A. (1997). Racismo y análisis crítico de los medios. Barcelona: Paidós.

Vieira, L (2014). O que tem sido divulgado pela imprensa local: Análise do conteúdo representacional do jornal Correio da Paraíba. 
Vliegenthart, Rens (2012). "Framing in mass communication research-an overview and assessment". Sociology Compass, 6(12): 937-948. Consultado el 30 de enero de 2017, disponible en doi: 10.1111/soc4.12003

Ward, Colleen; Szabo, Agnes y Stuart, Jaimee (2016). "Prejudice against immigrants in multicultural societies". En The Cambridge handbook of the psychology of prejudice. Cambridge University Press. Consultado el 10 de diciembre de 2016, disponible en https://doi. org/10.1017/9781316161579.018)

\section{RESUMEN CURRICULAR DE LOS AUTORES}

\section{Alba Marina González Martínez}

Licenciada en Psicología por la Universidad de Santiago de Compostela y Máster en Psicología Social por la Universidad Complutense de Madrid (España). Sus intereses de investigación se centran en el estudio de los estereotipos sociales y el prejuicio.

Dirección electrónica: Albamg02@ucm.es

Registro ORCID: https://orcid.org/0000-0003-0378-881X

\section{Iara Maribondo Albuquerque}

Doctorado en Psicología/Psicología Social por la Universidad Federal de Paraíba (Brasil) y la Universidad Complutense de Madrid (España). Máster en Psicología Social por Universidad Federal de Paraíba (Brasil). Ha desarrollado investigaciones en el campo de la Psicología Social, abarcando especialmente los siguientes temas: relaciones intergrupales, análisis psicosocial de los procesos de discriminación social, sexismo, valores y estereotipos sociales.

Dirección electrónica: iaramaribondo@gmail.com

Registro ORCID: https://orcid.org/0000-0002-4500-7391

\section{Khalil da Costa Silva}

Doctorado en Psicología/Psicología Social por la Universidad Federal de Paraíba (Brasil) y la Universidad Complutense de Madrid (España). Máster en Psicología Social por la Universidad Federal de Sergipe (Brasil). Ha desarrollado investigaciones en el campo de la Psicología Social, abarcando especialmente los siguientes temas: discriminación racial, procesos intergrupales y socialización infantil.

Dirección electrónica: klil_costa@hotmail.com

Registro ORCID: https://orcid.org/0000-0002-1339-7209 
José Luis Álvaro Estramiana

Es Catedrático de Psicología Social en el Departamento de Psicología Social de la Universidad Complutense de Madrid. Director de proyectos de investigación nacionales e internacionales, ha sido Affiliated Lecturer en la Universidad de Cambridge, donde ha impartido docencia y profesor invitado en diferentes Universidades europeas y latinoamericanas. Es autor de diversos libros entre los que cabe destacar Psicología Social. Perspectivas Psicológicas y Sociológicas (Ed. McGraw-Hill). Dirección electrónica: jlalvro@ucm.es

Registro ORCID: https://orcid.org/0000-0002-3017-030 